The Pakistan Development Review

35 : 4 Part II (Winter 1996) pp. 631—645

\title{
Pakistan: Ethnic Fragmentation or National Integration?
}

\author{
FEROZ AHMED
}

\begin{abstract}
In light of the current ethnic polarisation, this paper briefly enumerates the elements of ethnic conflict in Pakistan. It, then, discusses the economic, demographic, political, and cultural developments taking place in Pakistan which tend to affect the inter-relationships among ethnic communities and between society as a whole and ethnic communities. Evidence is presented to support the argument that despite surface tensions and confrontations, there is an unmistakable trend of greater inter-dependence which can contribute to national integration.

The paper further analyses the relationship between ethnicity, class, and the state. It identifies military, bureaucracy, capitalists, and landlords as the principal elements of the "ruling class", and shows that the different ethnic groups have different class structures and differential participation in military and bureaucracy. It points out the near absence of "cross cutting cleavages" which tends to turn the class and power conflicts into ethnic conflicts. In conclusion, the paper, while underlining the shifting definitional boundaries and relative demographic and cultural homogenisation of the population, argues against the redrawing of provincial boundaries and constitutional recognition of "nationality rights" of fixed ethnic groups. However, it makes a case for the recognition of ethnic diversity in Pakistan, equal treatment of all ethnic groups, and protection and promotion of the languages and cultures of the different ethnic groups. It argues that national unity, security, and integrity will be achieved if the primary emphasis is placed on promoting equity and harmony rather than on suppression of ethnic differences in the name of unity.
\end{abstract}

Pakistan has been beset with one of the gravest ethnic conflicts of its history. In 1995 alone, more than 1700 persons, including more than 200 law enforcement personnel, were killed in its major city, Karachi. ${ }^{1}$ A militant ethnic party in Sindh is in violent confrontation with the Government and other ethnic groups. Ethnic polarisation in the province of Sindh is almost complete, and in Balochistan it has shattered the traditional fraternity between ethnic groups. Violence and insecurity related to ethnic conflicts have seriously disrupted economic activities in urban Sindh where there has been evidence of flight of capital to other regions and shyness on the part of foreign capital to invest, besides billions of rupees lost each year due to recurrent strikes.

The late Feroz Ahmed was Professor in the School of Social Work, Howard University, Washington, D. C.

${ }^{1}$ Hosain, Yasser, "Whodunnit”? [sic], Newsline (Karachi), November 1995, pp. 46-48. 
The picture of Pakistan emerging from its ethnic situation reinforces the gloom and doom portrayed by its economic and political situation. On the surface, it looks as if ethnic and regional fragmentation is on the increase without mitigation. However, it is important to look at the other side of the coin, i.e., cooperation and integration, and look beyond the surface appearances.

Traditionally, Pakistan's ethnic diversity has been defined in terms of the existence of the four historical "nationalities", the Punjabis, Sindhis, Pushtoons and the Baloch, a major linguistic group, the Urdu-speaking people, and several smaller ethnolinguistic groups. Recently, however, a party representing the Urdu-speaking people in Sindh has demanded the "nationality" status for its group, while there has been a consistent demand from a section of the population in Punjab for the recognition of Siraiki-speaking people as a distinct "nationality". We have dealt with the question of ethnic identity elsewhere, and indicated our preference for the word ethnic group over nationality in order to avoid unnecessary conflict and appearance of a double standard. ${ }^{2}$ In this paper, we will briefly review the major issues in ethnic conflicts in Pakistan, the trends affecting changes in ethnic identity and issues, the intersection of ethnicity, the state and class, and the implications of these changes for national integration in Pakistan.

\section{MAJOR ISSUES IN ETHNIC CONFLICTS}

Much has been written about the history, facts, and legitimacy of ethnic grievances and ethnic competition in Pakistan. Here, we will only summarise the major elements of ethnic problems in Pakistan.

1. Sovereignty: Provincial rights, regional autonomy, and self-determination are the forms in which the "elites" of the dominated ethnic groups have raised grievances against the domination by the ruling class of Punjab. Demands for complete independence, confederation with only residual powers for the centre, greater autonomy within the federal structure, creation of new provinces for the groups not having their own province, and altering the provincial boundaries to create ethnically more homogenous provinces have been voiced from time to time. Lately, the demand for holding local elections and giving more power to local governments, especially in urban Sindh, has been added to the arsenal of ethnic demands.

2. Allocation of resources: This is perhaps the most important arena for struggle between provinces and between ethnic groups. The resources for which the contending parties struggle, include financial resources for development and

${ }^{2}$ Ahmed, Feroz, "Ethnicity, the State, and National Integration in Third World Societies: The Case of Pakistan". Paper read at the annual meeting of the American Sociological Association, held in New York on August 16-20, 1996. 
recurrent expenditures, share of irrigation water, Government jobs (the quota system), opportunities for professional and higher education (location of institutions and admission policies, allotment of agricultural lands in Sindh and Balochistan to military officers and civil bureaucrats.

3. Inter-province migration: There is great resentment in Sindh and some in Balochistan against the in-migration from Punjab and NWFP and immigration from other countries. In 1981, the census calculated a net migration-to-total population ratio of 9.6 percent for Sindh. ${ }^{3}$ Migration of such magnitude tends to put pressure on their limited resources and change the demographic balance.

4. Language and culture: demands for the protection and promotion of the languages and cultures of ethnic groups against the domination of Urdu and neglect of regional cultural heritage are a constant feature in the struggle of ethnic groups for their identity assertion. Cultural symbols serve as instruments of forging group cohesion and legitimating group demands.

\section{TRENDS AFFECTING ETHNIC CHANGE}

Several economic, demographic, social, political, and cultural trends which have been underway in Pakistan have significantly affected ethnic identification and ethnic issues. These changes have affected the ethnic question in the following principal ways: (a) status of certain ethnic groups; (b) inter-ethnic group relations; (c) relationship between state and ethnic groups; and (d) policy options pertaining to the ethnic questions.

\section{Economic change}

The most recent economic trends show continuing stagnation, balance of payments and reserves difficulties, paralysis of industrial and commercial activity in and flight of capital from Sindh due to political confrontation and violence, spiralling inflation, and deepening poverty. ${ }^{4}$ The trend of the decreasing role of manufacturing, mining, and agriculture, and a greater role of the service sector, foreign remittances, and illegal/underground economy, including heroin and gun trade, has continued unabated. Ethnic conflicts have also led to the ethnic segmentation of markets in parts of Sindh and Balochistan. Regional and inter-ethnic economic disparities created by

${ }^{3}$ Government of Pakistan, 1981 Census Report of Sindh. Islamabad: Government of Pakistan, 1984, p. 19.

${ }^{4}$ For recent economic difficulties and inflation, see two articles by Hussain, Zahid, "The Economic Squeeze", and "The Killer Spiral”, in Newsline, November, 1995. For an earlier article on the trend of flight of capital from Karachi, see Shiekh, Majid, "Flight from Karachi", Newsline, November, 1989. For continuing foreign investment in Karachi, despite a hopeless law and order situation, see Masood, Tahir, "The Investment Paradox”, The Herald, December 1995. 
Pakistan's pattern of economic development have been noted by scholars. ${ }^{5}$ Despite these negative trends, the overall thrust of economic growth and economic activities has, by and large, continued to be integrative of the capital, markets, and labour. Labourers, traders and transport operators from one set of provinces (Punjab and NWFP), by the millions, work in other provinces (Sindh, Balochistan, and Punjab).

A socio-economic trend of tremendous sociological importance is the change in class relations in agriculture. Much debate and discussion has taken place in South Asia about the nature and consequences of development in the agrarian economy. ${ }^{6}$ However, it is quite clear that despite persistence of archaic instruments of production, old oppressive class relations, social power of the big landlords, and traditional values, the agrarian system inherited at independence and conveniently labelled as feudal no longer exists. Capitalist development, with all its distortions and unevenness, has intruded into the agricultural sector of Pakistan's economy, if not supplanting, then grafting itself onto the old system. ${ }^{7}$ As a result of the technological changes, increased population density in the rural areas, and social changes facilitating alternative means of acquiring wealth and power, the traditional "feudal" class is no longer tied to the land, and its younger members are seeking a share in the professions, the capitalist sector of the economy, and state power, much the same way as other elements of the ruling class. Nor has its sways over the lives of the rural populace remained unchallenged and undiluted in the face of material productive and social changes and the revival of electoral politics. Since the class structure in different regions and among different ethnic groups varies quite substantially, the aforementioned changes are of great salience in the analysis of ethnic questions.

\section{Demographic Changes}

Uneven development of job opportunities has resulted not only in massive rural to urban migration within provinces, but large-scale inter-province migration, mainly from Punjab and NWFP, to Sindh. Continued existence of more than one million Afghan refugees has impacted the ethnic balance in Balochistan and affected the ethnic

${ }^{5}$ See, for example, Hamid, Naved, and Hussain, Akmal, "Regional inequalities and capitalist development: Pakistan's experience", and Kardar, Shahid, "Polarisation in the regions and prospects for integration” in Zahid, S. Akbar (ed.), Regional Imbalances and the National Question in Pakistan, Lahore: Vanguard, 1992, pp. 1-42, 306-333.

${ }^{6}$ For the famous mode of production debate in Economic and Political Weekly, see Patnaik Banaji, Rudra, Thorner, Chattopadhyay, et al., Studies in the Development of Capitalism in India. Lahore: Vanguard Books Limited, 1978.

${ }^{7}$ For analyses of transformation of class relations in agriculture, see Ahmed, Feroz, "Transformation of agrarian structures in Pakistan: the Punjab”, in Ngo Manh Lan (ed.), Unreal Growth: Critical Studies in Asian Development, New Delhi: Hindustan Publishing Corporation, 1984, Vol. II, pp. 606-639, Ahmed Feroz, "Transformation of agrarian structure in the North-West Frontier Province of Pakistan", Journal of Contemporary Asia, 14:1 (1984), pp. 5-47; Ahmed, Feroz, “Agrarian change and class formation in Sindh”, Economic and Political Weekly, 19:39 (Review of Agriculture), September 29, 1984. 
composition of other provinces. Settlement in Karachi of several thousand Biharis from Bangladesh and the presence of an estimated two million illegal immigrants from neighbouring countries have added to the economic, political, and demographic complexity of Karachi. As a result of these population movements, the proportion of both Sindhi and Urdu-speaking ethnic groups has continued to decline and that of Punjabis, Pushtoons, Siraikis, and others has increased in Sindh. In Balochistan, the ratio of Pushtoons to Balochs has increased. The NWFP has become even more Pushtoonised. The settlement of Pakistani Pushtoons and Afghan refugees, as well as illegal immigrants, in Punjab has had small effect on its ethnic composition, because of the large size of Punjab's population.

While urbanisation has increased in the country as a whole, its magnitude has been especially high in Sindh which, in the 1981 Population Census, was 43 percent urban. ${ }^{8}$ The proportion of urban population in Sindh may now be close to 50 percent, although there is no new census to verify it. The urbanisation of Sindh carries with it an ethnic dimension in that most of this growth, especially in Karachi, is among the "nonindigenous" groups, whereas the "indigenous" Sindhi and Baloch populations together comprise a little more than one-tenth of the population. ${ }^{9}$ This trend exacerbates the already existing urban-rural divide between Sindhis and Mohajirs. Although it is true that most (95 percent) of the Urdu-speaking people in Sindh are urban, it would be an over-simplification to categorise all Sindhis as rural. According to the 1981 Population Census, while 49.7 percent of the urban households in Sindh spoke Urdu, 18.3 percent spoke Sindhi and 3 percent spoke Balochi. For Sindh as a whole, 15 percent of all Sindhi-speaking households were urban. ${ }^{10}$

\section{Political Changes}

In a political system with a proliferation of political parties, and most parties having only regional pockets of support, the electoral process and the quest for power have required the building of alliances across not only ideological lines but across regional and ethnic lines. both within and among provinces. This political deal-making has engendered interesting examples of ethnic and regional interdependence and mutual trust among parties. Among the most interesting of these blocs is the one led by the Punjabi former Prime Minister Nawaz Sharif's Muslim League which has brought into its fold all the major Sindhi politicians opposed to Prime Minister Benazir Bhutto's PPP, and built alliances with both of the erstwhile Pushtoon nationalist parties, the Awami National Party of Wali Khan and the Pukhtoonkhwa Milli Awami

\footnotetext{
${ }^{8}$ Government of Pakistan, Statistics Division, Population Census Organisation, 1981 Census Report of Sindh, op. cit., p. 8

${ }^{9}$ Government of Pakistan, Statistics Division, Population Census Organisation, 1981 Population Census: District Reports: Karachi. Islamabad: Government of Pakistan, 1985, p. 103.

${ }^{10}$ Government of Pakistan, 1981 Census Report of Sindh, op. cit. pp. 9, 107.
} 
Party of Mahmood Achakzai, the remnants of the late Ghaus Bux Bizenjo's Balochbased Pakistan National Party, the mercurial Baloch leader Akbar Bugti's Jamhoori Watan Party, and the militant Mohajir nationalist MQM.

Bhutto's PPP, despite its waning popularity, still remains not only as the country's largest party, but a national party with the broadest regional and ethnic representation. The religious parties enjoy limited popular support and continue to squabble over sectarian and doctrinal issues, but they direct their appeals across regional and ethnic boundaries. The ethnic nationalist or separatist formations among Sindhi and Baloch ethnic communities seem to lack legitimacy and popular support within their own communities.

Despite intense ethnic conflict and fears of separatism in urban Sindh, the overall trend among politicians in Pakistan seems to be toward greater tolerance, interdependence, and political integration. The traditional politicians seem to have acquired the ability to share power and make money, and have little reason and time for intensifying ethnic and regional disputes, at least for now. However, several time bombs, including the proposed Kalabagh dam and the demand for creating a Mohajir province, remain that can rip apart the alliances of convenience, and throw the country into the flames of internecine warfare.

\section{Cultural Developments}

Several cultural trends have been underway that affect ethnic formation, ethnic relations, and national integration. The most interesting of these from the point of view of ethnic studies and national integration is the role of the Urdu language. Although Urdu is the mother tongue of only seven percent of Pakistan's population, historical circumstances have placed it in the position of being officially designated as the national language of Pakistan. The two major factors in favour of Urdu were the emergence of Urdu as a secondary symbol of Muslim identity in pre-independence India, ${ }^{11}$ and its adoption as the primary language of literacy and literary expression, against their own vernaculars, by all the ethnic groups of Pakistan, except Sindhis and, in limited areas, Pushtoons. ${ }^{12}$ Although protests continue to be voiced against the preeminence of Urdu, it has clearly established itself as Pakistan’s principal language of education, mass communication, politics, business, and inter-province coordination. An increasing number of Pakistanis whose mother tongue is not Urdu are learning to

\footnotetext{
${ }^{11}$ Brass, Paul R, Ethnicity and Nationalism: Theory and Comparison. New Delhi: Sage Publications, 1991, pp. 85-92.

${ }^{12}$ In 1961, for each person educated in Sindhi in Sindh, there were only 1.4 persons educated in Urdu. However, in NWFP, for each person educated in Pushto, there were 8 persons educated in Urdu. Similar ratios for Punjabi in Punjab and Balochi in Balochistan were 1:95 and 1:71 respectively. These ratios were computed from the figures provided in the Government of Pakistan, 1961 Population Census, Volume 3 (West Pakistan), Karachi: Manager of Publications, 1963.
} 
speak and understand it. In the 1961 Census, twice as many persons were reported to be speaking Urdu as persons whose mother tongue was Urdu. ${ }^{13}$ This type of data was not collected in the subsequent censuses. Nonetheless, the trend of linguistic assimilation to Urdu is unmistakable, as can be seen from the fact that 70.3 percent of the 14,745,234 literate persons in 1981 were literate only in Urdu. ${ }^{14}$

However, the impact of this assimilation is not uniform on different ethnic groups and in different regions. Concomitant cultural assimilation and Mohajir identity adoption by members of the Gujrati and Memoni Kutchchi-speaking small business communities in Karachi have been unmistakable. This may be considered one extreme of the linguistic assimilation to Urdu. At the other end, the Pushtoons may use Urdu in schools and for all kinds of written communication, but seldom do they adopt it as the language of the household. Similarly, the educated Balochs in Balochistan and urban Sindh have adopted Urdu without assimilating to it. The Punjabis have maintained their duality about language. They continue to consider Urdu as their own formal language, and many of the urban, educated individuals among them proudly proclaim Urdu to be their mother tongue and report it as such to the census enumerators. However, this linguistic assimilation has not been correlated with subjective identity transformation. On the contrary, Punjabi ethnic identity remains strong even in the urban areas, where a movement for the official status for Punjabi and its use as a written language is gaining ground.

While Sindhis have the longest and strongest tradition among the indigenous peoples of Pakistan to use their own language, and have been most resilient against the imposition of Urdu, they have not been altogether immune to the process of assimilation to Urdu. As a result of the overall influence of Urdu discussed earlier, as well as the compulsory teaching of Urdu to Sindhis, the non-availability of Sindhimedium schools in Karachi, and the domination of Urdu in the work place and the market in the major cities of Sindh, many Sindhi families have begun to speak Urdu at home and, when settled abroad, teach their children Urdu as a mark of their Pakistani identity. Further, when Sindhis and Urdu-speaking inter-marry, in most cases Urdu becomes the language of the household, regardless of who the husband or wife is. These developments are quite ironic in view of the demand of many Sindhi nationalists that the Urdu-speaking people speak Sindhi and assimilate into Sindhi culture. An opposite trend has also been noted in that, in reaction to the growing Mohajir political assertion in Sindh, even the cosmopolitan Sindhi families of Karachi, who had all but forgotten about their Sindhi roots, have begun to reassert their Sindhi identity, even though they may be speaking English or Urdu at home. This phenomenon gives credence to the theory of primordial identity being reawakened from the unconscious by certain triggers. ${ }^{15}$

${ }^{13}$ Government of Pakistan, 1961 Census of Population, Volume 3, op. cit.

${ }^{14}$ Government of Pakistan, Statistics Division, Population Census Organisation, 1981 Census Report of Pakistan (Census Report No. 69). Islamabad: Government of Pakistan, December 1984, p. 70.

${ }^{15}$ Brass, Ethnicity and Nationalism, op. cit. , p. 70. 
The trend of popular adoption of Urdu is giving rise to a paradoxical situation in which the term Urdu-speaking, which is used by many as more accurate and honorific than the term Mohajir for a specific ethnic group, may itself become a misnomer. Indeed, the Census of 1981 precisely tried to create this situation by asking a question about the "language usually spoken in the household" rather than about the mother tongue of the individual. This question, while biasing the response in favour of Urdu, underlines an interesting paradox: who is Urdu-speaking?

The integrating effects of Urdu have been correlated with the transmission through schools, literature, and the media certain social values and norms of behaviour, modelled after the culture of middle class immigrants from Utar Pradesh (India) or some unspecified group, which are deemed to be more "civilised" and desirable. Readers of Urdu novels and viewers of television dramas from all ethnic groups are subjected to a subliminal appeal to change their old ways in favour of these new mannerisms and attitudes. Thus, along with the development of a common language, a levelling of social values and norms of behaviour is also shaping across ethnic boundaries in Pakistan.

Through the agencies of mass media and the educational system, a religious homogenisation of sorts is also taking place among ethnic groups. The political system's increasing tendency to "Islamise" the state has resulted in standardising the understanding and practicing of Islam that tend to be more orthodox and strict about rituals than the sufiist and experiential beliefs and practices which were traditionally more common in Pakistan. This difference in religious experience has tended to coincide not only with class and urban-rural differences, but, given the overlap between ethnicity and class and between ethnicity and residence, it also coincides with ethnic differences. Therefore, the traditionally Sufiist Punjabi, Siraiki, Sindhi, and Baloch people feel obliged to assimilate into the religious beliefs and practices which are more common among the Urdu-speaking people, the urban Punjabi bourgeoisie, and the orthodox Pushtoons. Capitalist development, modernisation, national integration, the spread of education, and cultural homogenisation in Pakistan seem to be facilitating the gradual withering away of Sufiism and the ascendance of the scholastic Islam, which is often associated with the so-called fundamentalist movements.

The economic, demographic, political, and cultural trends discussed above will provide the backdrop for analysing the relation between ethnicity and state, and discussing policy implications.

\section{ETHNICITY, CLASS, AND THE STATE}

The state is both a resource in itself and a distributor of resources. ${ }^{16}$ In a multiethnic state, it is of importance to assess how these resources and state power itself are

\footnotetext{
${ }^{16}$ Brass, Ethnicity and Nationalism, op. cit., p. 272.
} 
shared by the different ethnic groups, and how state power might be used to the advantage of one or more ethnic groups and to the detriment of one or more of the other ethnic groups. Such an analysis, at first, requires an understanding of the nature of the state, the relationship of various classes to it, and the intersection between class and ethnicity. The view of the state taken in this writing is neither the one that treats it merely as a neutral arena where the interests of various interest groups are mediated, nor is it the classical Marxist approach which sees it as an instrument of oppression of one class by another and in which the executive branch of the state acts as a managing committee for the protection of the collective interests of the bourgeoisie.

The Pakistani state can be seen as a neocolonial state, linked as an appendage to the global capitalist economy and politically subservient to the United States. Within this abridged sovereignty the state, while perpetuating the existing relations of production and distribution, enjoys relative autonomy. The military and bureaucracy not only command the instruments of state power, but pursue their own interests almost independently of the dominant capitalist and landlord classes. The state, therefore, is neither above and detached from the society nor is it mechanistically subservient to the dominant classes. Because of the special locus and role of the educated middle class in the society and vis-à-vis the state, the latter accords it a privilege, or at least a sensitivity, that is not extended to the workers, peasants, and other subordinated classes. Further, in Pakistan's specific context, as in many Latin American, Asian, and African countries, the military is more than an equal of the civil bureaucracy and has acquired the role of the ultimate arbiter of political power. Furthermore, the pursuit of political power is not simply aimed at the protection of class and individual legitimate interests, but is also directed at the plunder of the state's resources.

Since the bourgeoisie and the landlord class are social classes, and the military and bureaucracy are wielders of the state apparatus, at one level of analysis it is important to keep the two separate. However, while analysing the class and power asymmetries in a multi-ethnic society, it becomes useful to treat both of these types as elements of a common aggregation. Therefore, while recognising that higher officials of the military and civil bureaucracy may be drawn from any class, we shall refer to the landlord class, the capitalist class, military, and bureaucracy as various elements of the "ruling class". This tentative usage is preferable to the term "elite", a favourite of many social scientists, because the latter becomes too broad and ambiguous by including social classes which are not economically or politically dominant. However, at a third level, where inter-ethnic group competition is analysed, the fact of the "ruling class" and the middle class of a given ethnic group combining to pursue their common interests calls for a common nomenclature. ${ }^{17}$ The term "elite" may be used to describe

${ }^{17}$ Brass, op. cit., analyses ethnic formation and ethnic conflicts in the conceptual framework of "elite competition”, pp. 25-36, 258-259. 
this broader aggregation which excludes workers, peasants, and other subordinated and marginalised classes.

\section{Intersection of Ethnicity and Class}

The different ethnic groups in Pakistan do not have an identical class composition. Nor do they have an equal, or even proportional, representation in the higher echelons of military and bureaucracy. Therefore, the various elements of Pakistan's ruling class have a disproportionate representation of the various ethnic groups in society. This situation represents a case, not of cross cutting cleavages, but of overlapping of class and ethnicity to a large extent. ${ }^{18}$

Demographically, the Punjabis comprise the largest single ethnic group (48.2 percent) in Pakistan's population, followed by Pushtoons (13.1 percent), Sindhis (11.8 percent), Siraikis (9.8 percent), Urdu-speaking (7.6 percent), Baloch-Brauhis (4.2 percent), and Hindko-speaking (2.4 percent). ${ }^{19}$ No statistics by ethnic group are available for the civil service and military ranks. However, it is an accepted fact that the officers and the rank and file of the armed forces are mainly Punjabi and Pushtoon, the former generally believed to be nearly 70 percent and the latter 25 percent to 30 percent. Urdu-speaking individuals continue to be in the higher ranks of the militarysuch as the former Army Chief of Staff, General Mirza Aslam Beg, but their representation is probably less than their population. There are no senior Sindhi or Baloch officers in the armed forces. Similarly, in the senior civil bureaucracy, the Punjabis and Pushtoons have a disproportionately high representation; the Urduspeaking, a one-time dominant fraction, have slipped but still maintain a proportionately large presence; the Sindhis, despite some recent appointments to high positions, are still under-represented; and the Balochs, also under-represented, are too small a group to have any influence even if given a proportional share.

The ethnic composition of the dominant classes is also asymmetrical. The capitalist class of Pakistan consists mainly of Punjabis and members of the small business communities who have migrated from Gujrat and Bombay and who have now begun to identify themselves as Mohajir. The Pushtoons are well represented in all strata of the capitalist class, having established businesses in all four provinces, and substantially controlling inter-province and intra-province transportation. The lucrative gun and heroin business is also mainly controlled by Pushtoons. Traditionally, there have been only a few big Urdu-speaking capitalist, but an Urdu-speaking bourgeoisie is well-entrenched, owning medium and small businesses. Although two Sindhi business families are among the richest in Pakistan, and a few have the potential of

\footnotetext{
${ }^{18}$ For a theory of cross-cutting cleavages, see Bentley, Arthur F., The Process of Government. Cambridge (MA): Harvard University Press, 1967.

${ }^{19}$ Main Findings of the 1981 Population Census. Islamabad: Government of Pakistan, 1983, p. 13.
} 
transforming themselves, with the help of the plunder of the state resources, into capitalists, there is no Sindhi bourgeoisie to speak of. Similarly, there is no Baloch capitalist class.

The landlord class, which continues to be of analytical and political interest, also has an uneven presence among different ethnic groups. In absolute numbers and economic, social, and political power, first come the landlords of lower and western Punjab, most of whom are Siraiki-speaking, but closely integrated with the Punjabi ruling class. The current President of Pakistan, Farooq Leghari, is a good example. Next come the landlords of Sindh, who in the absence of a Sindhi bourgeoisie and a strong middle class, enjoy the position of being economically, socially, and politically the most powerful class of the Sindhi society. Feudal-type relations of production still persist in parts of NWFP, and there are many powerful Pushtoon landlords. However, the more prominent of them also have business investments and a presence in the armed forces and bureaucracy. Probably, the Pushtoon ruling class is the most wellrounded ruling class. Many of the traditional Baloch sardars (tribal/clan chiefs), by usurping communal lands and privileges, have turned themselves into landlord; but most sardars are of modest means who depend upon Government's largesse for their well-being. Although the more prominent sardars of Balochistan have established alliances with the Punjabi landlords of Balochi "racial" stock (the Legharis and Mazaris), the national influence of Baloch chieftains is quite limited.

Finally, the relative strength of the educated middle class, which provides most of the personnel for white-collar professions and the pool for recruitment into civil service and military, also varies greatly among the different ethnic groups. The absolute and relative size of this class is very much a function of the differentials in the population size and the extent of higher education in the different ethnic groups. The Punjabis, both because of their population size and relatively extensive higher education, have the largest educated middle class in absolute numbers. However, the Urdu-speaking community, because of its historical background, urban residence, and traditional reliance on education for social mobility, has an educated middle class which is larger than that of any other ethnic group relative to other classes within the ethnic group, and also the largest in Pakistan in terms of the group's population proportion. This is indicated, among other things, by the fact that while Punjab, comprising 56 percent of Pakistan's population, produces 14,000 college graduates per year, Sindh, with 22.6 percent of the population, produces about 12,000 graduates, a majority of whom are Urdu-speaking. ${ }^{20}$ The middle class among Pushtoons and Sindhis is much less developed than among Punjabis and Urdu-speaking people, but is expanding rapidly. The Baloch middle class is still rudimentary, but gaining influence within its own ethnic group.

\footnotetext{
${ }^{20}$ Kardar, Shahid, "Polarisation in the regions and prospects for integration”, in Zaidi (ed.), Regional Imbalances and the National Question in Pakistan, op. cit., pp. 306-333.
} 


\section{DISCUSSION AND CONCLUSIONS}

It has been shown in the above analysis that while ethnic polarisation in Sindh and Balochistan has intensified recently, because of the past and present internal and international migrations, the trend seems to be towards greater ethnic heterogeneity in different parts of Pakistan. Given this fact, and the growing economic and political interdependence, and increasing cultural homogenisation, it has become imperative and even possible to seek solutions to regional and ethnic problems in a multi-ethnic framework. For example, redrawing of provincial boundaries, which might have been possible in the early years of Pakistan, is no longer a problem-solving option. Similarly, the idea of constitutional recognition of Pakistan as a multi-national or multi-ethnic state with clearly identified groups and group rights, which has been articulated as a political demand, and which may sound like a rational approach to dissipate ethnic tensions, may not necessarily produce the desired results.

Assumption of fixed definitional boundaries or fixed number of ethnic groups may pose serious problems in the future even if a consensus on categories and number could be achieved at present. On the other hand, the present segmented approach may provide a more realistic basis for addressing ethnic problems, provided, (a) all the major elements of the ethnic problem are recognised and addressed broadly by constitutional provisions and concretely through public policies, (b) mechanisms for implementing and monitoring the relevant legal provisions are put in place, and (c) effective judicial process is made available to enforce compliance.

Internal migration and urbanisation are world-wide phenomena, determined by population growth and uneven development. Although the process of urbanisation, particularly in Sindh and Balochistan, is taking place to the demographic and economic detriment of the local population, it would be a fallacy to view the urbanisation phenomenon as an ethnic menace. However, in order to mitigate the divisive effects of urbanisation, non-coercive preventive and remedial actions would be needed. Policies directed towards slowing down the flow of inter-province migration would require both slowing down of population growth rate and focusing on job-creating projects in the source areas of migration (NWFP and Punjab). However, rural-urban migration within provinces is unavoidable. Rural job creation programmes and expansion of urban housing and civic amenities would be the key ingredients of policies directed towards addressing this problem.

International migration—mostly illegal—contributes to population growth rate, urbanisation, ethnic diversification, competition for resources, social unrest, and political tensions. The ratio of immigrants to the total population in 1981 was 4.8 percent for Pakistan, 5.8 percent for Punjab, and 6.2 percent for Sindh. ${ }^{21}$ By all indications, the volume of illegal migration and refugee influx has increased

\footnotetext{
${ }^{21}$ Government of Pakistan, Main Findings of 1981 Population Census, op. cit., pp. 5, 15 (computed).
} 
substantially in all the provinces since 1981. The Government finds itself helpless to curb this migration. The immigrants, in their struggle to survive, get caught up in the vortex of ethnic politics. Public awareness can force the hand of the Government to curb illegal immigration. However, it can also aid and abet illegal immigration from the neighbouring countries if the motive is to increase the numbers of their own ethnic group.

Undoubtedly, the ethnic asymmetries within Pakistan's "elite" and the substantial overlapping of class and ethnicity pose the greatest challenge to removing ethnic disparities and promoting harmony and national integration. Given the ethnic specificity of the armed forces and the spending of the largest portion of the budget on defence, a more equitable distribution of resources among ethnic communities is unthinkable without drastically altering the ethnic composition of the military and/or reducing the military budget. The civil bureaucracy has been more amenable to ethnic diversification, and given sufficient political pressure, the bureaucracy can be made to be more inclusive. However, Government rules and the attitude of the government of the time have a considerable bearing on who gets recruited and promoted in the bureaucracy. The few gains made by Sindhis recently can be easily reversed by the Government which might succeed Prime Minister Benazir Bhutto, not only because many of these appointments are thought to be motivated by favouritism, but the successor Government might be based on the support of the MQM which will most certainly demand an increased share for "Mohajirs", calculated on a fantastic percentage in the population: 50 percent of Sindh's population, which comes out to be 11.3 percent of Pakistan's population. ${ }^{22}$

Beside the subjective attitudes of the Government in power, there are serious "structural" facts concerning ethnicity and class which tend to complicate otherwise simple issues of ethnic parity. The Urdu-speaking community's urban, middle class character, and its current lower middle class leadership, present some unique problematic. First, ethnic movements are usually based on grievances of the disadvantaged groups concerning ethnic disparities. By all objective indicators, the Urdu-speaking community is anything but a disadvantaged ethnic group, and it had always been considered by the general public as well as political analysts as a relatively privileged group, along with Punjabis. However, since the mid-1980s, a militant nationalist movement has galvanised the Urdu-speaking population which sees itself as the most deprived and oppressed group in Pakistan. ${ }^{23}$

This chasm between reality and perception has intrigued many an analyst. One could find parallels between this movement and those of the Sikhs, Croats, Afrikaners, and other groups, and attribute it to the "relative" "deprivation theory" or "false

\footnotetext{
${ }^{22}$ This demand has been included, among other documents and statements, in the MQM's 15-point charter of demands. The News (Karachi), January 12, 1995.

${ }^{23}$ For an analysis of the rise of the Mohajir movement, see Ahmed, Feroz, "Ethnicity and politics: The rise of Mohajir separatism”, South Asia Bulletin, 8:1\&2 (Spring/Fall 1988), pp. 33-45.
} 
consciousness" of a better-off group. ${ }^{24}$ Here, however, we are not engaged in analysing the causes of any specific movement, but to point a problematic of ethnicityclass nexus that a specific ethnic movement in Pakistan poses. What the MQM dilemma underlines is the inadequacy of looking at "class as a whole" and "ethnic group as a whole". The Urdu-speaking people, "as a whole", can certainly not be viewed as a group at the bottom rungs of the ladder of privileges. Nor can the middle class — even the lower middle class — be viewed as a deprived class in comparison with the multitudes of impoverished and destitute peasants, workers, and other poor. The Urdu-speaking lower middle class, having struggled hard to get higher education, found the avenues for jobs and advancement blocked. It followed the model of the deprived or dominated groups (Bengali, Sindhi) to blame ethnic discrimination for is plight rather than following the model of the dominant (Punjabi) group of blaming the "system" or class oppression. It manipulated the cultural symbols of its group to mobilise the rest of the classes of its ethnic group in a militant nationalist movement. The job situation of the "Mohajir" lower middle class, like the by-passing of Sindhi peasants for land allotment and Sindhi workers for jobs in the new industries in Sindh, underlines the fact that there is more to the ethnic problem than just "elite competition", even if the educated middle class proper is included in that "elite".

Second, in popular view a middle class leadership, in contrast to the "oppressive and exploitative" feudal or capitalist leadership, is generally held to be more legitimate. The MQM is never tired of stressing the contrast between its middle class character and the "feudal" character of the PPP's leadership, with the implication that all of the MQM's demands can only be legitimate and any share given to Sindhis is nothing more than an illegitimate feudal expropriation. The coding of ethnic hatred behind leftist rhetoric by a right-wing organisation is an interesting development engendered by the conflict between two ethnic communities led by markedly different classes. The political supremacy of the landlord class - a function of its traditional economic and social power - and the relative weakness of the middle class among Sindhis, forces the latter class not only into dependence on the former, but subjects it to a burden of constantly proving to the people of Pakistan the legitimacy of its rights.

Third, one of the most important sources of tension between provinces is the share of irrigation water and the differential impact of constructing new dams. Although the Urdu-speaking members of Sindh Assembly, so far, have tended to vote along with Sindhi members in defence of the province's rights, the water problem is not perceived by the Urdu-speaking people as a "life and death problem" the way it is seen by the people directly dependent on agriculture. Although this may just be an expected indifference of the urban population, in Sindh's specific context, ethnic motives are readily attached to such attitudes. On the other land, the landlord

${ }^{24}$ For these and related theories, see Brass, Ethnicity and Nationalism, op. cit., pp. 41-48. 
leadership's lack of understanding of and insensitivity toward pressing urban problems in a highly urbanised province like Sindh immediately acquires an ethnic dimension.

In Balochistan, the conflict between Balochs and Pushtoons, after a long history of political cooperation, burst out recently in the form of armed clashes. Whatever else may have been the specific reasons for these incidents, it is not difficult to see how the differentials in the class structure between Balochs and Pushtoons may have put the latter in an advantageous position to avail itself of the professional opportunities and the spoils of the state. While the Balochs still have extensive remnants of nomadic life and a strong clan organisation, the Pushtoons have a weaker tribal control and a relatively large educated middle class.

The overlapping of class and ethnicity, by preventing the formation of crosscutting cleavages, not only makes inter-ethnic collaboration more difficult, it promotes class collaboration within the groups which perceive themselves to be threatened from outside. As a result of the rising ethnic consciousness, the real challenge—as opposed to the empty ethnic codified diatribes - to the oppressive feudal-type system in the countryside has weakened substantially.

While national integration is a desirable goal, the primary emphasis on integration in the past has led to oppressive policies about ethnic diversity and disparities. On the other hand, if the primary emphasis is placed on promoting equity and harmony among different ethnic groups, national unity, security, and integrity would be the logical outcomes. Suppression of ethnic rights in the name of security, unity, or integrity of the country will have the opposite effect. 